\title{
DIGITALCOMMONS
}

@WAYNESTATE-

Wayne State University

Human Biology Open Access Pre-Prints

WSU Press

$7-1-2020$

\section{Narratives of Injustice: An Investigation of Toxic Dumping within the Blackfeet Nation}

\author{
Kimberly L. Paul \\ University of Montana, Piikani Lodge Health Institute \\ Laura B. Caplins \\ Nature-Link Institute
}

Follow this and additional works at: https://digitalcommons.wayne.edu/humbiol_preprints

\section{Recommended Citation}

Paul, Kimberly L. and Caplins, Laura B., "Narratives of Injustice: An Investigation of Toxic Dumping within the Blackfeet Nation" (2020). Human Biology Open Access Pre-Prints. 173.

https://digitalcommons.wayne.edu/humbiol_preprints/173

This Article is brought to you for free and open access by the WSU Press at DigitalCommons@WayneState. It has been accepted for inclusion in Human Biology Open Access Pre-Prints by an authorized administrator of DigitalCommons@WayneState. 


\title{
Narratives of Injustice: An Investigation of Toxic Dumping within the Blackfeet Nation
}

Kimberly L. Paul $1,2 *$ and Laura B. Caplins3

1University of Montana, Missoula, Montana, USA.

${ }_{2}$ Piikani Lodge Health Institute, Blackfeet Nation, Browning, Montana, USA.

3Nature-Link Institute, Florence, Montana, USA.

*Correspondence to: Kimberly L. Paul, P.O. Box 187, Piikani Lodge Health Institute, Blackfeet

Nation, Browning, Montana 59417 USA. E-mail: kpaul@piikanilodge.org.

Short Title: Narrative of Injustice within the Blackfeet Nation

KEY WORDS: BLACKFEET, AMSKAPI PIIKANI, ENVIRONMENTAL JUSTICE, ENVIRONMENTAL RACISM, CONTAMINATED WASTE DUMPING, CANCER CLUSTERS, TOXIC EXPOSURE.

\begin{abstract}
For over 50 years, the people of the Amskapi Piikani Nation (Blackfeet) have relayed information of "something bad" being covertly dumped within their remaining homelands. These stories, addressing contaminated waste and the locations of rumored dump sites, have also been linked with perceived cancer clusters among residents who live within the Blackfeet Nation. The concept of environmental justice suggests that often the most vulnerable populations, to include communities of color, experience the negative realities of environmental toxic exposures and it is
\end{abstract}


not uncommon for toxic wastes to be disposed of within Native lands. Given that Blackfeet communities suffer from some of the highest rates of cancer incidence in the state of Montana, (MT Tumor Registry, 2018) these narratives warrant further investigation. This research asks if illicit dumping within Blackfeet sovereign lands can be substantiated and if this is a case of environmental injustice. This investigation employs a mix of both traditional Indigenous and western-based scientific methodologies, both quantitative and qualitative. Traditional methodologies include the use of Indigenous oral narratives. These oral narratives are then further informed with western process, to include document review, geologic, water, and radiation surveys. The study finds compelling evidence through the oral histories and document reviews for the potential of toxic dumping within Blackfeet lands, however, cursory water and radiation surveys are not conclusive. This initial inquiry provides the foundation for further research needed to press this investigation. 
Amskapi Piikani history has been passed down via oral tradition for hundreds of generations. These creation stories place the Blackfeet in the territory where they remain today. Their natural rhythm of life was in the seasonal movement of camps and the summertime gathering together of their many bands. This was and is the way of the Confederated Blackfoot Tribes, the Siksikaitsitapi, "the Original People". This traditional relay of information from generation to generation is accepted as fact, not just anecdotal tales. Today, this oral history also communicates stories of health disparities and injustice.

For over 50 years, the Blackfeet people of Montana have relayed information of "something bad" being covertly dumped within their remaining homelands. These stories, addressing contaminated waste and the locations of rumored dump sites, have also been linked with perceived cancer clusters among residents (BirdRattler 2019; Kennerly 2019; Kipp 2019). These oral history accounts of clandestine dumping within Blackfeet Country warrant further investigation, especially considering the high incidence of cancer within these areas.

This study investigates the possibility of dumping on Blackfeet lands through the documentation of oral histories regarding toxic waste being buried in Blackfeet country. This study also includes document reviews dating back to when the dumping was reported to have occurred by oral history. Finally, preliminary water sampling and radiation surveys were conducted in suspected areas to see if contaminants could be found which supported the oral histories.

This manuscript first introduces the Blackfeet people, the literature on environmental justice, and Native American health disparities. Narratives of injustice are then documented and initial water sampling and radiation survey results presented. Finally, the results and limitations of this study are discussed, including next steps. 


\section{Blackfeet Lands and People}

The Amskapi Piikani are the southernmost members of an independent confederation of four Blackfoot warrior tribes of the Northern Plains. The four different member nations of the Blackfoot Confederacy are the Aapatohsi Piikani, the Siksiká, the Kainai and the Amskapi Piikani. The Amskapi Piikani are the only tribe of the Blackfoot Confederacy that were restricted to what is now known as the United States, with the other three tribes being located in Canada.

The current Blackfeet populace numbers 17,250 strong (Blackfeet Tribe 2019). They are the largest tribal population within Montana and the tenth largest tribe in the nation, with the median resident age being 30 years (Blackfeet Tribal Health Department 2017). There are nine distinct, small outlying communities within the Blackfeet's remaining land base of about 1.5 million acres.

The expansive Blackfoot Confederacy diminished with the coming of immigrating peoples from the east, north and south. It was not that the Blackfeet lost a series of battles, but rather were tormented by varied and continuous assaults. The government took native lands. The people were exposed to diseases to which they had no immunity. The nation's vast herds of buffalo were slaughtered, leaving a starving people (Haley 1976). Alcohol was introduced and children were forcibly removed and sent to boarding schools (Still Smoking 1997). In 1870 a surprise early morning massacre of a camp of hundreds of elders, women and children. These combined events rapidly decimated pre-contact numbers to only 2,000 individuals in the late 1880s (Spence 1996). These horrific acts were not purely a result of culture collision with nonNatives, but were part of a systematic, organized governmental plan to extinguish and marginalize Indigenous peoples, their land-base and their identity (Jaime 1992, Paul 2015, 
Prucha 2000). This genocidal history, forced assimilation practices, and the cultural and societal changes that came with numerous Presidential Acts and governmental policies have left the Blackfeet facing grave health challenges today. Health disparities often occur in line with racial divides and can be further exacerbated by environmental injustices (Bigham and Non 2015).

\section{Environmental Justice and Illegal Dumping on Native Lands}

We employ the concept of environmental justice to help contextualize the Blackfeet claims of toxic dumping on their lands. We review cases of toxic exposures on native lands to demonstrate how dumping on native lands is not by happenstance, but rather due to targeted outreach.

The Environmental Justice Movement began when it became clear that communities of color were subjected to higher rates of toxic exposure than surrounding white communities (Vasudevan 2013). Environmental justice tenets assert that there should be equality in the exposure of different populations to environmental risks, that communities are able to engage in

meaningful participation in environmental decision-making, and that community Ways of Being and Knowing are recognized (Schlosberg 2007).

Native peoples are but one vulnerable population of people whom experience environmental injustice via the dumping of toxic waste products within their lands. The following instances of toxic dumping better contextualize the prevalence of the practice.

The Western Shoshone's Yucca Mountain in Nevada was marked for a nuclear waste site (Harden and Morgan 2004). The Skull Valley Band of the Confederated Tribes of the Goshute in Utah were targeted for the storage of radioactive nuclear fuel waste, with the community already being exposed to a hazardous waste landfill and incinerators, toxic storage facilities and plants, power plants, and biological weapons testing grounds (Allen 2014; Endres 2009; EJA 2016; 
Hoffman 2001; Hanson 2001). The Navajo/Diné, Hopi, Paiute, and Zuni Uranium Mines in Arizona, New Mexico, and Utah saw extensive mining activities with no remediation though local populations suffer from disproportionate kidney failure, cancer, and uranium poisoning (Hunter et al. 2015; CDC 2018). The Confederated Tribes and Bands of the Yakama Nation, the Confederated Tribes of the Umatilla Nation, the Wanapum, and the Nez Perce Tribes have all been affected by the release and leaking of irradiated by-products from the Hanford Nuclear Site, causing exponentially high incidence of thyroid and throat cancers, and encephalopathy (CDC 2018). These undeniable patterns of the exploitation of people and their lands are clearly examples of environmental racism, showing a very real history of targeted illegal dumping of toxic waste products on Native lands (Hanson 2001).

\section{Native Health Disparities and Toxic Dumping}

The level of dangerous environmental exposure for Native Americans in and around these sites is significantly increased. This increase is complicated by already staggering health disparities for Native peoples over non-Natives. Native peoples in the US are at a greater risk of dying from preventable death: suicide, accidental death, diabetes, liver disease, certain cancers, respiratory disease, and homicide (IHS 2019). The average life expectancy of Natives in Montana is between 15 and 20 years shorter than their non-Native counterparts living just a few miles away (Belcourt 2018; Blackfeet Tribal Health Department 2017). Such disparities are caused by complex issues including lack of access to quality healthcare, few employment opportunities, resultant lower socio-economic status, generational poverty and trauma, and the ensuing high incidence of alcohol and drug misuse, compounded by Native communities being targeted by drug cartels. 
The Blackfeet experience cancer rates disproportionately higher than their non-Native neighbors (Paul 2015). The association of cancer incidence and mortality can be looked at from a few different foci: lack of access to timely and quality healthcare, predominance of cancers diagnosed in third or final stages, tobacco use in Blackfeet population, or environmental exposures to carcinogenic chemicals or compounds (ACS 2018).

Environmental health issues related to toxic exposures within the Blackfeet population are not well documented. This lack of documentation is due in part to the fact that toxic dumping on Blackfeet lands has not yet been proven. It is our hope that this paper begins to fill this void, and raises the need for further investigation in this area. The current literature contains no data referencing environmental health studies related to toxic or nuclear waste within Blackfeet Country, nor any published studies relating environmental contaminants to cancer. Therefore, how these intersecting factors affect the Blackfeet people remains unclear.

What is clear from our review of the literature is that toxic waste dumping has systematically taken advantage of western Native peoples. This targeting of Native communities to toxic chemicals also included Blackfeet lands. While the Blackfeet suffer from health disparities like many other Native communities, it is affected by a uniquely high prevalence of cancer that is currently unexplained. No investigation of the connection between the high levels of cancer within Blackfeet Country and the possible connection to exposure of carcinogenic waste materials exists (ATSDR 2011).

\section{Methods}

Four methods to investigate the presence of nuclear waste within the Blackfeet Nation included the; 1) recording of surviving oral histories, 2) document surveys, 3) radiation investigations of 
sites rumored or suspected to be disposal sites, and 4) water testing from wells, ponds, creeks, and rivers under the Hudson Bay Divide region to survey for residual radioactivity.

1. Oral Histories are appropriate Indigenous methodologies for gathering historic information. Traditional methods of knowledge transfer include stories shared from older generations to younger ones. Oral history accounts of adults who reside within the Blackfeet Nation, who were young children at the time of the dumping, were recorded. Oral histories included first-hand accounts of children witnessing suspicious events, young adults retelling stories of unusual behavior, and elders' warnings against entering particular geographic areas. We collected approximately 27 stories which fell into these three categories. The stories were collected through in-person interviews of individuals living within the Blackfeet Nation.

2. Document Survey examined Department of Defense (DOD) repositories, Hanford archival data, personal accounts for local Clergy, Blackfeet Tribal Council meeting minutes, museum archival data, and senatorial and congressional data.

3. Radiation Monitoring If radioactive waste from the Hanford site were dumped in Blackfeet Country then indication of this dumping could include isotopes from the production of plutonium. These isotopes include some parent uranium and plutonium materials plus their radioactive decay daughter sequences. Radiation survey measurements were conducted at the abandoned Del Bonita Radar site, on the Hudson Bay Divide Ridge and down-gradient towards lower St. Mary Lake. The instrument employed was a hand-held RPI (Research Products International Corporation) RadMonitor Model GM-1 Radiation/Contamination Survey Meter. The RPI meter includes a 
high sensitivity scintillation probe for detecting low energy gamma emitters such as 125Iodine.

4. Water Sampling events began within a 20-mile radius of the suspect Hudson Bay Divide area, encompassing 26 sample sites in the area of the perceived cancer cluster. Sampling was limited to surface and well water from ridge drainage (aquifer and spring fed) and encompassed all creeks, beaver dams, ponds, and home-site wells. Sampling rounds were gathered via $25-\mathrm{mL}$ scintillation vials and transported back to the University of Montana for analysis under chain of custody protocol. Selection of sampling sites was guided by familial cancer patterns. A liquid scintillation counter was employed to quantify the presence of various radionuclides. The water samples were prepared at a 4:1 ratio of Econo-SafeTM scintillation cocktail solution to sample water. Mixed samples were counted via Beckman LS 6500 Multipurpose Scintillation Counter possessing a 32,768channel analyzer with an effective resolution of $0.06 \mathrm{keV}$; pre-programmed to measure ${ }_{3} \mathrm{H}$ and ${ }_{14 C}$. In addition, a "wide" spectrum setting was used to encompass the entire spectral range of the instrument. Two counting runs were done: one immediately after loading the vials into the instrument and the second after the samples had been enclosed in the dark for 17 hours. This second run was to assess measurable effect from visible light on the radionuclide counts.

\section{Waste and Contamination within the Blackfeet Nation}

\section{Oral Histories of "Something Bad" Being Buried on Blackfeet Lands}

As a child the first author remembers accounts of "something bad" being buried within Blackfeet Country. As children, they instructed not to pick medicines, flowers, and plants in specific areas. 
This generational knowledge was passed on from her grandmothers and grandfathers. These instructions were supported by other community voices suspecting the same areas of contamination.

The oral histories we captured for this investigation revealed multiple accounts of "the big trucks loaded with barrels" in remote areas of the Blackfeet Nation where there were few roads, expansive dug-out sites remembered as "bottomless pits", and uniformed men "driving big trucks loaded with barrels" 40 miles from town asking for directions. All the oral histories reported these activities occurring at night and lend themselves to covert dumping activities.

One woman remembers when she was a child in the 1960's, seeing loaded trucks coming to her grandparent's home near Heart Butte at night. Men in uniforms asked for directions, and even though their grandfather sent them back to bed, they watched the headlights of many trucks for a long time.

Another elder remembers in the late 70's a security guard who worked at the tribal office shared that he had been taken him from his duties and brought to a place at the north end of the west side of lower St. Mary Lake. He was given a two-way radio and instructed to remain at the dirt road, radioing an alert if anyone was to pass. He then "stood guard" while a truck with a "low boy loaded with a backhoe" and other trucks loaded with barrels (all driven by men in uniforms) went up into the area. He shared that he was out there for a long time then brought back to town. He was very embarrassed by this forced action.

Local stories about dumping usually implicated the Del Bonita corridor, Hudson Bay Divide Ridge, Boulder Ridge, Kiowa Camp and near Heart Butte including the Four Horn or Owl Child Lake area (Bremner, 2015; Running Crane, 2011; Wetselline, 2018). 


\section{Damning Documents}

In the Northwest Museum of Arts and Culture in Spokane, Washington a search of the Sister Providencia Tolan documents found Folder 29 labeled “Atomic Waste Disposal Proposal for the Blackfeet Reservation”, dated July 19, 1961; to include - Petroleum Research Corporation's Proposal to the Blackfeet Tribal Business Council. This document, written by the Petroleum Research Corporation (PRC), proposed to the Blackfeet Tribal Business Council to dump not less than 50,000,000 gallons of irradiated waste-water (1961) within the boundaries of the "Blackfeet Reservation", stating that it was the tribe's civic duty to accept this waste. PRC proposed a price/gallon and core drills into the land for waste injection (PCR 1961). Further, the proposal notes a geologic survey undertaken the year prior, proving the landscape "safe for injection" (PRC 1961). Contaminated waste was to be transported from the Hanford sites in Eastern Washington.

During this same period there are telegrams to then sitting Montana Senator Mansfield, from communities and their members external to the Blackfeet Nation, decrying the tribe's potential acceptance of the toxic waste. Among the many telegrams was one from a "whistle blower" who applauded the "gumption" of the Tribal Council in turning down the PRC proposal, and also told of "a white man named Black accepting this radioactive waste within the Blackfeet Reservation" (Black 1962).

Blackfeet Tribal Council meeting notes show that the proposal is formally turned down in 1962. At the end of the year of deliberation - a short quote from Old Fish Wolf Robe who stands up and strikes his staff on the floor to interrupt the Council meeting and says in Piikani (paraphrasing) "I may not speak good English, but my grandson here does. He can tell you that I don't want to talk about all these other things...I want to talk about the things you want to bury 
here for money...the radiation that can cause earthquakes and harm our people and damage our land" (BTC 1962).

\section{Radiation Measurements}

No notable radiation measurements were detected other than those consistent with existing background radiation levels (ATSDR 2011).

\section{Water Sampling}

Given the calibration of the equipment, evidence of atomic waste would show up in the residual plot. Residuals were not overwhelming in any sample. The average tritium content across the sample set was $21.4 \mathrm{cpm}$. The average Carbon-14 (14C) level was $12.7 \mathrm{cpm}$. With the wide-open average at $45.3 \mathrm{cpm}$, the average of the residual counts was 11.1, less than either the naturally occurring tritium $(3 \mathrm{H})$ and ${ }_{14} \mathrm{C}$. No samples gathered in these rounds implicated a water source as dangerously contaminated with radionuclides. An examination of the data revealed no systematic error. Both runs appear to be valid counts. The runs were averaged to reduce uncertainty.

\section{Discussion}

In learning further about the history of the Amskapi Piikuni people and other native communities' interactions with the U.S. government and private industry in relationship to toxic waste it becomes plausible that through the Blackfeet Tribal Council turned down the proposal to accept radioactive waste burial that clandestine dumping did occur.

Pre-print version. Visit http://digitalcommons.wayne.edu/humbiol/ after publication to acquire the final version. 
Through this study, oral history accounts were collected indicating "something bad" was buried on tribal lands. These incidents were estimated to have occurred around 1961/1962 on the western and northern periphery of Blackfeet lands.

This investigation unearthed written evidence of an attempt by the Atomic Energy Commission's sub-contractor Petroleum Resource Corporation to enter into an agreement with the Blackfeet Tribal Council, dated July 19, 1961. The proposal sought to bury a minimum of fifty million gallons of Hanford Engineer Works radioactive waste water derived from the production of plutonium. It was deliberated on by the Blackfeet Tribal Council from July of 1961 to June of 1962, and then refused. It is not known if any perfunctory dumping took place during this year of deliberation. A record was discovered connecting a non-tribal member with accepting the contaminated waste water, for burial on his land within the Blackfeet Nation (Black 1962). County plat records verify that this same non-Blackfeet had gained ownership of much of the Hudson Bay Divide Ridge area. A potential cancer cluster exists within the drainage area of Hudson Bay Divide Ridge.

Radiometer surveys at both the Hudson Bay Divide Ridge area and the Del Bonita Radar Station did not detect radiation above what is expected for background levels. Cursory water samples were gathered from a twenty-mile area at the base of the Hudson Bay Divide Ridge. Analysis of these samples revealed no radionuclides present at levels substantially different from those of naturally occurring tritium and ${ }_{14} \mathrm{C}$. The reasons for these findings are discussed further in the Study Limitations.

We are not able to conjure up any additional explanations for the oral histories collected and detailed in this study. Other possible explanations for the high rates of cancer include potential genetic predisposition and tobacco use. 


\section{Study Limitations}

The water sample testing was severely constrained by lack of funding to conduct a more extensive study for other plutonium production by-product isotopes. Time was donated on an instrument that was crucial to several other funded research projects so it could not be recalibrated to target uranium or plutonium production radionuclides which were of more interest to this project. Due to this inability to fully analyze the water for all known $235 \mathrm{U}$ enrichment product isotopes, analysis was isolated to only two. Instruments capable of identifying product waste in $235 \mathrm{U}$ enrichment would also include $131 \mathrm{I}$ and 89, 90, $94 \mathrm{Sr}$ and $135 \mathrm{Cs} .131 \mathrm{I}$, with half-life of eight days is disintegrated. However, $129 \mathrm{I}$ and ${ }_{135} \mathrm{Cs}$, plus other products of breeder production of uranium have half-lives of 15.7 million years and 2.3 million years respectively. $90 \mathrm{Sr}$ with halflife of thirty years might also still be detectable if a contamination event occurred in the early 1960’s.

The isotopes shared above are just some of the examples of the hundreds of radionuclides produced within a fission reaction enriching uranium up to plutonium. In addition, the examples above are among the shorter decaying, less stable byproducts, which decay into other isotopes, half-life after half-life. Less stable fission products unfortunately decay into further unstable isotopes (more radioactive), leaving hundreds of isotopes to test for and find.

Furthermore, there were challenges to assessing cancer incidence in Glacier County via Montana Tumor Registry, as all cancer occurrences within the county are not divided between Blackfeet Nation population and the rest of Glacier County. However, the authors were awarded a Tribal Council Resolution (2019), affording them the access to all de-identified health records within the Blackfeet Nation, for a continuation of this research. 
Also, even though every family who had traditionally lived along the 12-mile stretch of runoff from Hudson Divide Ridge experienced death and incidences of cancer, this area has not been designated a cancer cluster site, as all primary cancers were not the same (Aldrich and Sinks, 2002). This was compounded by inadequate access to Indian Health Service (IHS 2019) Health and Mortality Records at the time of this study.

Overcoming these limitations serve as the basis for future work.

\section{Conclusion}

Through our investigations we have uncovered the interest of a subcontractor of the government in toxic dumping on Blackfeet lands in 1961, though permission was denied by the Blackfeet Tribal Council. Furthermore, through documented oral histories regarding "something bad" being dumped on Blackfeet lands and document reviews we have revealed the possibility of clandestine contamination events. This study has also suggested next steps for further investigation of toxic dumping and the designation of cancer clusters on Blackfeet lands. This cursory study was however incapable of proving or disproving the hypotheses that dumping from Hanford Atomic Works occurred in the 1960's in the areas the cancer clustering suggests.

Research of this nature can help to better establish connections between dumping of toxic waste on Native lands and Native health disparities, while serving as a warning to vulnerable populations. These linkages can also be used to better leverage remediation needed to prevent future disease and help to raise the health and well-being of Native peoples within the bounds of the Blackfeet Nation, but also around the world.

Other Native communities that have experienced similar incidents are encouraged to document their experiences. Through the systematic documentation of such narratives we may 
be able to prove that some of the profound health disparities faced by Native peoples are in fact due to environmental injustices. Highlighting these instances of injustice can help to shift the blame of the causes away from the individual and towards environmental exposure. The shift can enable individuals and communities to better garner resources to adequately support those in need and to uncover areas of contamination to protect communities and biosystems from further exposure.

\section{Acknowledgements}

We are eternally grateful to the many helpers we had along the way. There were so many Blackfeet community members who assisted in this investigation and Dr. Sandy Ross whose support never wavered.

Received 31 June 2019; accepted for publication 4 May 2020. 


\section{Literature Cited}

Agency for Toxic Substances and Disease Registry (ATSDR). 2011. Public Health Assessment for Hanford Site, Richland, Benton County, Washington, EPA Facility ID:WA3890090076, May 17, 2011. Springfield, VA: ATSDR.

Aldrich, T. E., and T. H. Sinks. 2002. Things to know and do about cancer clusters. Cancer Invest. 20:810-816.

Allen, S. J. 2014. A Mighty Wind: Nerve Gas, Six Thousand Dead Sheep, and Soviet Trickery. Washington, D.C.: Capital Research Center.

American Cancer Society (ACS). 2018. http://www.cancer.org.

Belcourt, A. 2018. The hidden health inequalities that American Indians and Alaskan Natives face. The Conversation, 25 January.

Bigham, A. W., and A. Non. 2015. The genetic anthropologist's contribution to understanding race and racial health disparities. Hum. Biol. 87:291-293.

BirdRattler, L. 2019. Personal interview with K. Paul.

Black, H. 1962. Series 17-99/5 EDA - Indians - Blackfeet-Miscellaneous - Blackfeet Atomic Waste Burial (Telegram to Senator Mansfield). Missoula, MT: Maureen and Mike Mansfield Library and the University of Montana.

Blackfeet Nation. 2017. Blackfeet Reservation Timeline: Blackfeet Tribe. Helena, MT: Montana Office of Public Instruction, Indian Education Division.

Blackfeet Nation. 2019. https://blackfeetnation.com/.

Blackfeet Tribal Health Department. 2017. Community Health Assessment: Blackfeet Reservation. Browning, MT: Blackfeet Tribal Health Department.

Blackfeet Tribal Council (BTC). 1962. Tribal Council Meeting Notes. Browning, MT: BTC. 
Bremner, J. 2015. Personal interview with K. Paul.

Center for Disease Control (CDC). 2011. A Prospective Birth Cohort Study Involving Environmental Uranium Exposure in the Navajo Nation. Springfield, VA: CDC, ATSDR, and the Navajo Nation.

Endres, D. 2009. From wasteland to waste site: The role of discourse in nuclear power's environmental injustices. Local Environ. 14:917-937.

Environmental Justice Atlas (EJA). 2016. Radioactive Waste on Skull Valley Goshute Indian Reservation, USA. https://ejatlas.org/conflict/radioactive-waste-on-skull-valley-goshuteindian-reservation-usa.

Haley, J. 1976. The Buffalo War: The History of the Red River Indian Uprising of 1874. Norman, OK: University of Oklahoma Press.

Hanson, R. D. 2001. An experiment in (Toxic) Indian capitalism: The Skull Valley Goshutes, new capitalism, and nuclear waste. Polit. Leg. Anthropol. Rev. 24:25-38.

Harden, B., and D. Morgan. 2004. Debate intensifies on nuclear waste. Washington Post, 2 June. Hoffman, S. M. 2001. Negotiating eternity: Energy policy, environmental justice, and the politics of nuclear waste. Bull. Sci. Technol. Soc. 21:456-472.

Hunter, C. M., J. Lewis, M. G. Begay et al. 2015. The Navajo birth cohort study. J. Environ. Health 78:42-45.

Indian Health Service (IHS). 2019. Indian Health Disparities. Rockville, MD: IHS.

Jaimes, A. 1992. The State of Native America: Genocide, Colonization, and Resistance. Boston, MA: South End Press.

Kennerly, R. 2019. Personal interview with K. Paul.

Kipp, S. 2019. Personal interview with K. Paul.

Pre-print version. Visit http://digitalcommons.wayne.edu/humbiol/ after publication to acquire the final version. 
Paul, K. L. 2015. Stories of contaminated waste dump sites in Amskapi Piikani Blackfeet Country. Master's thesis, University of Montana.

Petroleum Research Corporation (PRC). 1961. Petroleum Research Corporation Proposal for Atomic Energy Commission: Burial of Irradiated Waste from Hanford Engineer Works. Spokane, WA: Sister Providencia Tolan Collection of the Northwest Museum of Arts and Culture.

Prucha, F. P. 2000. Documents of United States Indian Policy. 3rd ed. Lincoln, NE: University of Nebraska Press.

Running Crane, O. 2011. Personal interview with K. Paul.

Schlosberg, D. 2007. Defining Environmental Justice: Theories, Movements, and Nature. Oxford, UK: Oxford University Press.

Spence, M. 1996. Crown of the continent, backbone of the world: The American wilderness ideal and Blackfeet exclusion from Glacier National Park. Environ. Hist. 1:29-49.

Still Smoking, D. M. 1997. Tribal education: A case study of Blackfeet Elders. PhD diss., Montana State University.

Vasudevan, P. 2013. Memory and the re-invention of place: The legacies of environmental justice in Warren County, North Carolina. Master's thesis, University of North Carolina. Wetselline, K. A. 2018. Personal interview with K. Paul. 
Table 1. Liquid Scintillation Counter Results

Sample Cancer $\quad$ H-3 $\quad$ C-14 Wide $\quad$ W- $(\mathrm{H}+\mathrm{C})$

$\begin{array}{llllllllll}\# & \text { Incidence } & \mathrm{cpm} & \mathrm{sd} & \mathrm{cpm} & \mathrm{sd} & \mathrm{cpm} & \mathrm{sd} & \mathrm{cpm} & \mathrm{sd}\end{array}$

$\begin{array}{llllllllll}1 & - & 24.0 & 5.7 & 12.5 & 0.7 & 47.0 & 7.1 & 10.5 & 2.1\end{array}$

$\begin{array}{llllllllll}2 & - & 25.0 & 5.7 & 15.5 & 0.7 & 52.0 & 2.8 & 11.5 & 2.1\end{array}$

$\begin{array}{llllllllll}3 & - & 16.5 & 0.7 & 9.0 & 1.4 & 34.0 & 2.8 & 8.5 & 3.5\end{array}$

$\begin{array}{llllllllll}4 & 1 & 20.5 & 3.5 & 14.0 & 1.4 & 45.5 & 4.9 & 11.0 & 0.0\end{array}$

$\begin{array}{llllllllll}5 & - & 21.5 & 3.5 & 14.5 & 3.5 & 45.5 & 4.2 & 9.0 & 2.8\end{array}$

$\begin{array}{llllllllll}6 & 1 & 26.0 & 5.7 & 13.0 & 2.8 & 53.5 & 3.5 & 14.5 & 0.7\end{array}$

$\begin{array}{llllllllll}7 & 2 \text { (now 3) } & 17.0 & 1.4 & 13.5 & 4.9 & 39.0 & 8.5 & 8.5 & 2.1\end{array}$

$\begin{array}{llllllllll}8 & 1 \text { (liv) } & 16.0 & 2.8 & 14.5 & 2.1 & 43.5 & 0.7 & 13.0 & 0.0\end{array}$

$\begin{array}{llllllllll}9 & 1 & 17.5 & 6.4 & 11.0 & 0.0 & 42.0 & 5.7 & 13.5 & 0.7\end{array}$

$\begin{array}{llllllllll}10 & - & 23.0 & 2.8 & 11.0 & 1.4 & 49.0 & 0.0 & 15.0 & 1.4\end{array}$

$\begin{array}{llllllllll}11 & - & 19.0 & 8.5 & 10.5 & 4.9 & 39.5 & 7.8 & 10.0 & 5.7\end{array}$

$\begin{array}{llllllllll}12 & - & 22.0 & 0.0 & 11.5 & 0.7 & 46.5 & 4.9 & 13.0 & 4.2\end{array}$

$\begin{array}{llllllllll}13 & 1 & 23.0 & 2.8 & 12.5 & 2.1 & 42.0 & 2.8 & 6.5 & 3.5\end{array}$

$\begin{array}{llllllllll}14 & 1 & 25.0 & 1.4 & 15.0 & 2.8 & 49.0 & 1.4 & 9.0 & 0.0\end{array}$

$\begin{array}{llllllllll}15 & - & 22.0 & 2.8 & 15.0 & 1.4 & 46.0 & 4.2 & 9.0 & 2.8\end{array}$

$\begin{array}{llllllllll}16 & 1 & 20.5 & 2.1 & 9.5 & 3.5 & 41.5 & 0.7 & 11.5 & 2.1\end{array}$

$\begin{array}{llllllllll}17 & 1 \text { (now 2) } & 22.5 & 0.7 & 11.5 & 3.5 & 44.5 & 2.1 & 10.5 & 2.1\end{array}$

$\begin{array}{llllllllll}18 & 1 & 19.5 & 0.7 & 10.5 & 0.7 & 44.0 & 2.8 & 14.0 & 1.4\end{array}$

$\begin{array}{llllllllll}19 & 4(3 \text { liv }) & 17.0 & 4.2 & 9.5 & 0.7 & 36.0 & 5.7 & 9.5 & 2.1\end{array}$

$\begin{array}{llllllllll}20 & - & 24.5 & 3.5 & 11.0 & 1.4 & 46.0 & 8.5 & 10.5 & 6.4\end{array}$ 


$\begin{array}{rccccccccc}21 & - & 22.0 & 1.4 & 16.0 & 1.4 & 49.0 & 4.2 & 11.0 & 4.2 \\ 22 & - & 25.5 & 10.6 & 14.0 & 5.7 & 52.5 & 19.1 & 13.0 & 2.8 \\ 23 & - & 16.5 & 3.5 & 13.5 & 3.5 & 40.5 & 0.7 & 10.5 & 0.7 \\ 24 & - & 26.5 & 7.8 & 14.0 & 1.4 & 51.0 & 8.5 & 10.5 & 2.1 \\ 25 & - & 21.5 & 3.5 & 16.5 & 0.7 & 49.5 & 0.7 & 11.5 & 4.9 \\ 26 & 2 \text { (now 3) } & 22.0 & 5.7 & 12.0 & 2.8 & 48.5 & 10.6 & 14.5 & 2.1\end{array}$




\section{Figure Captions}

Figure 1. Locations of cancer incidence that informed water sampling.

Figure 2. Locations of water samples taken.

Pre-print version. Visit http://digitalcommons.wayne.edu/humbiol/ after publication to acquire the final version. 


\section{Figure 1.}

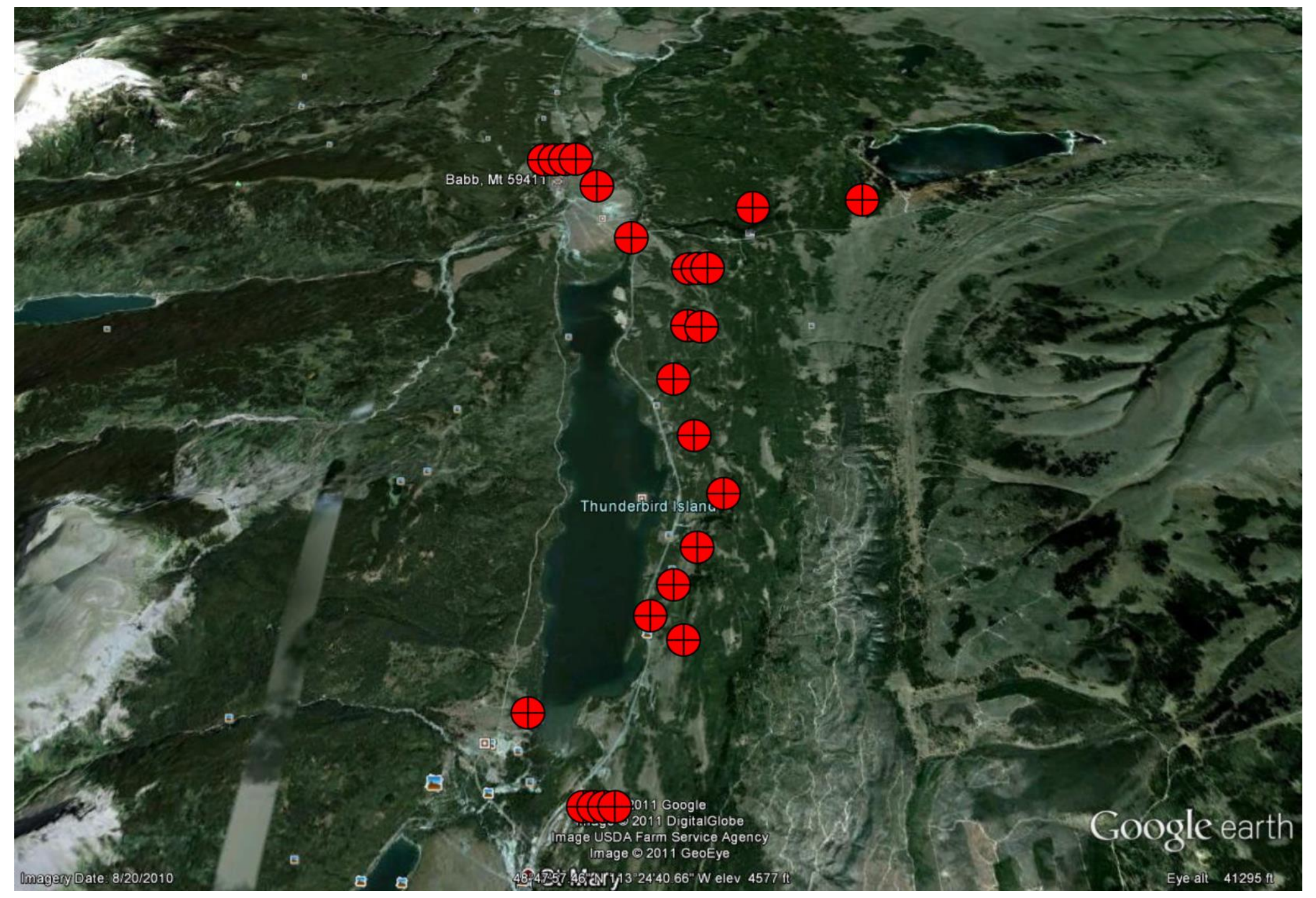

Pre-print version. Visit http://digitalcommons.wayne.edu/humbiol/ after publication to acquire the final version. 


\section{Figure 2.}

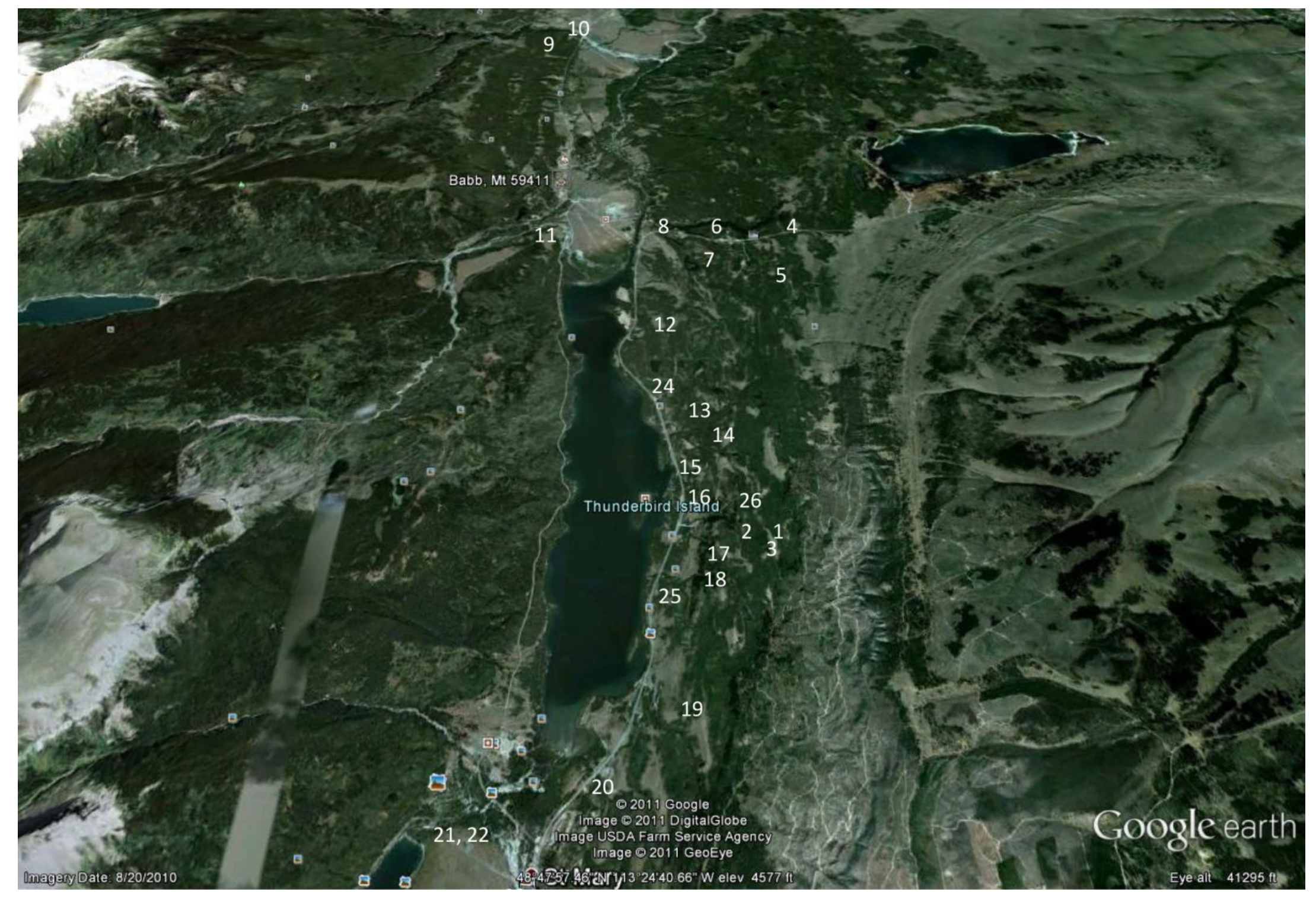

Pre-print version. Visit http://digitalcommons.wayne.edu/humbiol/ after publication to acquire the final version. 